\title{
INTENSI BERWIRAUSAHA MAHASISWA DI KOTA PEKANBARU
}

\author{
MUTIA ULFAH \\ Sekolah Tinggi Ilmu Ekonomi Persada Bunda Pekanbaru \\ Jl. Diponegoro No.42 Pekanbaru \\ Email: mutiaulf@gmail.com
}

\begin{abstract}
Though Entrepreneurial intentions have been extensively researched in the West, the question of their applicability in the local setting still remains. Intention of young generation on entrepreneurship in Pekanbaru still unclear. The purpose of this paper is to asses the entrepreneurial intentions among Pekanbaru undergraduate students. Using data from 96 respondents with random purposive sampling this study found that Entrepreneurial intentions among Pekanbaru' undergraduates were significantly come from internal factor (motivation, behavior, work orientation, creativity and innovation) and External factors (family and society, academic, and technology. Results show variable that used in this study explain $66,9 \%$ of entrepreneurial intentions. The finding suggests that higher educational institutions should develop a change of academic curriculum with focus on practical implications by integrate the change of mindset, skills, and abilities about entrepreneurship in the general academic in order to nurture undergraduate's entrepreneurial intentions in Pekanbaru
\end{abstract}

Keywords: Entrepreneur, Entrepreneurial Intentions, Pekanbaru

Beberapa dekade terakhir, kajian terkait kewirausahaan telah menjadi bidang yang menarik bagi para peneliti dan pemerintah di seluruh dunia tak lain tak bukan karena meningkatnya persaingan global, pesatnya kemajuan teknologi, dan juga ekonomi pasar yang berkembang. Kewirausahaan sering kali dipandang sebagai cara paling relevan untuk menghadapi persaingan global dan memahami bagaimana kaum millennial mulai terjun ke dunia wirausaha. Wirausahawan atau biasa dikenal dengan sebutan entrepreneurs memainkan peranan penting dalam membawa perubahan dan kemajuan ekonomi suatu negara. Jumlah entrepreneurs di suatu negara kerap dianggap sebagai indikator kemajuan suatu negara. Semakin tinggi jumlah entrepreneurs, semakin tinggi tingkat kemajuan negara tersebut. Syarat untuk menjadi negara maju yakni apabila negara tersebut memiliki jumlah entrepreneurs diatas angka $14 \%$ dari rasio penduduknya. Sementara di Indonesia, jumlah pelaku enterpreneurs masih berada di angka $3,1 \%$ sehingga perlu diadakan percepatan dan kemudahan agar pelaku ekonomi Indonesia bisa meningkat jauh dan mendekati persyaratan sebagai negara maju. Kontribusi entrepreneurs terhadap pembangunan ekonomi telah dibahas oleh Baron dan Shane dalam Entrepreneurship: A Process Perspective (2008) bahwa "entrepreneurs merupakan mesin pertumbuhan ekonomi suatu negara".

Indonesia sebagai salah satu negara yang sedang berkembang di wilayah Asia, saat ini sedang menikmati dividen demografis dimana $69 \%$ populasi penduduk Indonesia berada dalam usia kerja produktif 15-64 tahun. Populasi kerja yang signifikan ini menjadi tantangan bagi Pemerintah Indonesia untuk dapat menciptakan lapangan kerja termasuk mendorong kewirausahaan. Kendati secara agregat angka pengangguran di Indonesia menurun, tapi dilihat dari tingkat pendidikannya lulusan diploma dan universitas makin banyak yang tidak bekerja. Jumlah pengangguran terdidik yang semakin tinggi di Indonesia saat ini menjadi perhatian khusus pemerintah. Berdasarkan laporan BPS 
(2018) tingkat pengangguran intelektual Indonesia terus meningkat dari tahun ke tahun. Saat ini tingkat pengangguran intelektual terbuka lulusan universitas sudah mencapai angka $6,31 \%$ dan tingkat pengangguran lulusan diploma sebesar $7,92 \%$.

\section{Zimmerer (2002) menyatakan} bahwa salah satu faktor pendorong pertumbuhan kewirausahaan di suatu negara terletak pada peranan perguruan tinggi melalui penyelenggaraan pendidikan kewirausahaan. Pihak perguruan tinggi bertanggung jawab dalam mendidik dan memberikan kemampuan wirausaha kepada para lulusannya dan memberikan motivasi untuk berani memilih berwirausaha sebagai karir mereka. Pihak perguruan tinggi perlu menerapkan pola pembelajaran kewirausahaan yang kongkrit berdasar masukan empiris untuk membekali mahasiswa dengan pengetahuan yang bermakna agar dapat mendorong semangat mahasiswa untuk berwirausaha (Yohnson, 2003; Wu \& Wu, 2008).

Hal ini juga menjadi salah satu alasan perubahan landscape ekonomi Jokowi dalam upaya pengentasan pengangguran intelektual dengan menetapkan kewirausahaan sebagai salah satu mata kuliah wajib pada perguruan tinggi sesuai UU No.12 Tahun 2012. Menggalakan kewirausahaan di kalangan peseta didik di perguruan tinggi diyaknini sebagai salah satu strategi yang bisa diterapkan untuk menanggulangi masalah tersebut. Diharapkan para lulusan perguruan tinggi tidak hanya berorientasi sebagai job seeker tapi juga dapat menjadi entrepreneurs muda terdidik yang mampu merintis usahanya sendiri dan siap menjadi job creator. Secara khusus, penciptaan lapangan kerja merupakan sebagai salah satu kontribusi utama para entrepreneurs. Selain itu, pemerintah Indonesia sedang dan terus berusaha menciptakan berbagai program kewirausahaan dan merampingkan kebijakan bisnis untuk UMKM guna mendukung iklim kewirausahaan.
Self-employed atau enterpreneurs beberapa tahun belakangan ini menjadi popular sebagai pilihan karir. Bahkan baru-baru ini entrepreneurs sudah digaungkan sebagai alternatif karir yang menarik di mata para peserta didik di seluruh dunia (Schwarz et al, 2009). Secara harfiah, enterpreneurship, selfemployed dan start-up business memiliki makna yang kurang lebih sama (van Gelderen et al, 2008).

Presiden Jokowi dalam acara penganugerahaan Wirausaha Mandiri di Jakarta sejak 2015 lalu sudah menyatakan tantangannya agar masyarakat Indonesia khususnya generasi muda agar lebih banyak yang melebarkan sayap untuk berwirausaha. Kebijakan Ekonomi Presiden Jokowi saat ini lebih berfokus menggiatkan ekonomi kreatif sebagai tulang punggung dan pilar perekonomian Indonesia untuk kedepannya. Sejalan dengan perubahan landscape ekonomi Indonesia saat ini, membuka peluang besar bagi lahirnya banyak wirausaha muda terutama pada generasi millennial.

Kobia dan Sikalieh dalam Towards a Search for The Meaning of Entrepreneurship (2010) menyebutkan bahwa kajian kewirausahaan merupakan kajian yang masih baru dan dirasa perlu untuk melakukan penelitian lebih lanjut. Schwarz et al (2009) juga menyatakan bahwa dalam penelitian terkait kajian kewirausahaan, adalah sangat penting untuk memahami faktor-faktor apa yang mempengaruhi niat seseorang berwirausaha.

Selain itu, teori konvensional terkait "traditional trait" mungkin tidak berlaku untuk iklim entrepreneurs saat ini karena para peneliti dengan suara bulat setuju bahwa entrepreneurs dihasilkan, tidak dilahirkan. (Boulton dan Turner, 2005; Mellor et al., 2009) dimana sebenarnya entrepreneurs dapat diasah dan dilatih. Oleh karena itu, adalah penting untuk melihat faktor-faktor apa saja yang membuat seseorang tertarik untuk menjadi entrepreneurs dan isu 
terkait tumbuh kembang entrepreneurs. Mencari tahu penentu niat berwirausaha adalah langkah penting dalam mengidentifikasi cara menumbuhkembangkan entrepreneurs' yang kompetitif di Indonesia.

Niat berwirausaha sudah banyak diteliti di Negara Barat, namun di Indonesia sendiri, penelitian terkait Kewirausahaan masih terbatas meskipun kewirausahaan telah dipandang penting dalam pengembangan dan pertumbuhan ekonomi. Menerapkan hasil studi negara Barat di Indonesia khususnya di kota. Pekanbaru pasti akan menimbulkan pertanyaan-pertanyaan lainnya terkait kesesuaian dalam penerapannya. Meskipun beberapa peneliti lokal telah mencoba untuk mempelajari niat berwirausaha di Indonesia, beberapa batasan dapat ditemukan dalam penelitian tersebut.

Melihat fenomena di atas, maka penulis ingin mengetahui faktor-faktor pendorong yang mempengaruhi minat berwirausaha di kalangan mahasiswa khususnya di Pekanbaru.

Para peneliti sebelumnya sepakat bahwa entrepreneurs dibuat dan tidak dilahirkan (Boulton dan Turner, 2005; Mellor et al., 2009) dimana sebenarnya entrepreneurs dapat diasah dan dilatih. Seperti yang sudah dibuktikan oleh Krueger et al dalam tulisan berjudul Competing Models of Enterepreneurial Intentions (2000) menyatakan bahwa kegiatan kewirausahaan adalah kegiatan yang dimulai dengan disengaja, dimana untuk menjadi entrepreneurs pada awalnya bermula dari niat dan tujuan tertentu hingga mereka menjadi salah satunya. Dengan kata lain, seseorang tidak akan menjadi entrepreneurs secara tiba-tiba tanpa ada alasan tertentu yang menjadi pemicu dan tentu saja yang paling penting adalah niat atau kemauan.

Pada dasarnya pembentukan jiwa kewirausahaan dipengaruhi oleh faktor internal dan eksternal (Priyanto, 2008). Faktor internal yang berasal dari dalam diri entrepreneur dapat berupa sifat-sifat personal, sikap, kemauan dan kemampuan individu yang dapat memberi kekuatan individu untuk berwirausaha. Sedangkan faktor eksternal berasal dari luar diri pelaku entrepreneur yang dapat berupa unsur dari lingkungan sekitar seperti lingkungan keluarga, lingkungan dunia usaha, lingkungan fisik, lingkungan sosial ekonomi dan lain-lain.

Penelitian ini bertujuan untuk melihat faktor-faktor penentu entrepreneurial intentions dengan menggabungkan dua pendekatan yaitu: 1) faktor internal: motivasi, kepribadian, orientasi kerja, kreatifitas dan inovasi; 2) faktor eksternal lingkungan keluarga \& sosial, lingkungan akademik, lingkungan teknologi.

\section{METODE}

Dalam penelitian ini, yang menjadi populasi adalah seluruh mahasiswa perguruan tinggi baik negeri maupun swasta di Pekanbaru. Dikarenakan jumlah populasi yang tidak diketahui secara pasti, peneliti menggunakan pendekatan Lemeshow untuk menghitung jumlah yang layak dijadikan sebagai responden.

$$
n=\frac{\mathbb{Z} \alpha^{2} \times \mathbb{P} \times \mathbb{Q}}{\mathbb{L}^{2}}
$$

Keterangan:

$$
\begin{array}{ll}
n & =\text { jumlah sampel } \\
\mathbb{Z} \alpha^{2}= & \text { nilai standar dari distribusi dengan } \\
& \text { nilai } \alpha=5 \%=1,96 \\
\mathbb{P} & =\text { prevalensi outcome, karena data } \\
& \text { belum didapat, maka dipakai } 50 \% \\
\mathbb{Q} & =1-\mathbb{P} \\
\mathbb{L} & =
\end{array}
$$
$10 \%$, maka diperoleh jumlah responden yang dibutuhkan dalam penelitian ini yakni sebanyak 96 orang.

Proses Pengembangan Instrumen dilakukan melalui uji coba instrumen Entrepreneurial Intentions untuk mengetahui apakah instrumen layak digunakan dalam penelitian melalui uji keterbacaan untuk mengetahui efektifitas kalimat yang digunakan pada setiap item 
sehingga meminimalisasi kesalahan yang mungkin terjadi karena kurang sesuainya tujuan peneliti dengan pemahaman calon responden penelitian. Pada penelitian ini uji keterbacaan dilakukan pada 5 orang mahasiswa tahun kedua, 3 orang mahasiswa tahun ketiga, dan 2 orang mahasiswa tahun akhir yang dipilih secara acak pada salah satu institusi pendidikan tinggi; dan tidak mengalami perubahan susunan kalimat.

Analisis yang akan digunakan dalam penelitian ini adalah analisis deskriptif terhadap data kualitatif dan analisis statistik untuk data-data yang bersifat kuantitatif. Untuk karakteristik sosio demografi seperti jenis kelamin, umur, asal perguruan tinggi, diukur dengan pertanyaan dikotomi, dengan menggunakan skala pengukuran nominal.

Untuk menganalisis tentang adanya pengaruh faktor internal, faktor eksternal terhadap entrepreneurial intentions mahasiswa digunakan teknik analisis regresi linier berganda dengan bantuan program SPSS for Windows versi 24.

$$
\mathbf{Y}=\mathbf{a}+\mathbf{b}_{1} \mathbf{X}_{1}+\mathbf{b}_{2} \mathbf{X}_{2}+\mathbf{e}
$$

Dimana:

$$
\begin{array}{ll}
\mathrm{Y} & =\text { Entrepreneur Intentions } \\
\mathrm{a} & =\text { Konstanta } \\
\mathrm{b} & =\text { Koefisien Regresi Variabel Bebas } \\
\mathrm{X}_{1} & =\text { Faktor Internal } \\
\mathrm{X}_{2} & =\text { Faktor Eksternal } \\
\mathrm{e} & =\text { error }
\end{array}
$$

\section{HASIL}

Berdasarkan karakteristik demografi, jumlah responden hampir merata dari segi jenis kelamin dan didominasi oleh laki-laki. Sebagian besar responden berusia dibawah 25 tahun dan mayoritas berasal dari perguruan tinggi swasta dengan latar belakang pendidikan ekonomi. Mayoritas sebanyak 56,3\% mahasiswa yang menjadi responden belum pernah bekerja sebelumnya, adapun mahasiswa yang bekerja sebagian besar berasal dari perguruan tinggi swasta dan $6,2 \%$ diantaranya ada yang sudah memiliki usaha sendiri

\section{Uji Validitas}

Berdasarkan hasil uji validitas, diperoleh $r_{\text {tabel }}>r_{\text {hitung; dimana nilai } r} r_{\text {tabel }}$ sebesar 0,200 dengan uji dua arah taraf siginifikan 0.05 untuk setiap item maka semua pernyataan tersebut dinyatakan valid dan dapat digunakan dalam penelitian ini.

\section{Uji Reliabilitas}

Berdasarkan hasil pengolahan data diketahui bahwa reliabilitas yang diperoleh adalah lebih besar dari 0,6 sehingga instrumen penelitian ini dinyatakan reliabel dan layak digunakan dengan derajat reliabilitas Sedang.

Tabel 1: Regresi Linear Berganda

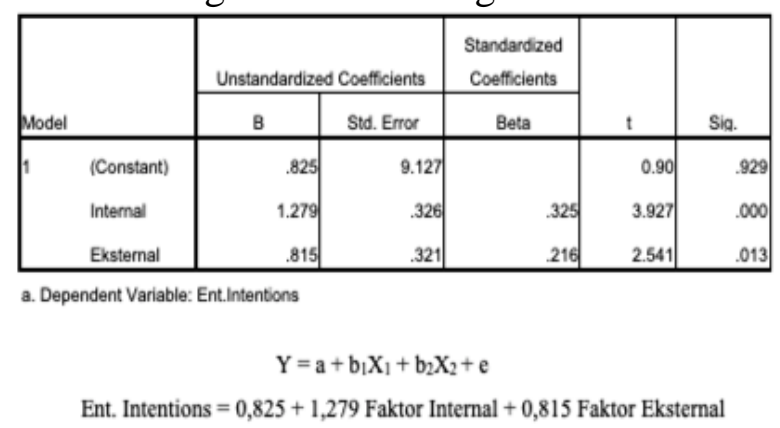

Dari model regresi berganda terlihat nilai konstanta sebesar 0.825 , nilai tersebut menjelaskan bahwa jika faktor internal dan eksternal tidak mengalami perubahan maka entrepreneurial intentions di kalangan mahasiswa di Pekanbaru adalah sebesar 0.825 .

\section{Uji T (t-Test)}

Dengan menggunakan t-test, diperoleh nilai $t_{\text {hitung variabel faktor internal }}$ $\left(\mathrm{X}_{1}\right)$ sebesar 3.927 sedangkan $\mathrm{t}_{\text {tabel }}$ sebesar 1.987, dengan demikian $t_{\text {hitung }} 3.927>t_{\text {tabel }}$ 1.987 dan nilai signifikansi sebesar 0,000 ( sig < 0,05). Berdasarkan analisis di atas disimpulkan bahwa faktor internal berpengaruh secara signifikan terhadap entrepreneurial intentions mahasiswa di Pekanbaru sehingga hipotesis ini telah teruji secara empiris.

Nilai $t_{\text {hitung }}$ variabel faktor eksternal $\left(\mathrm{X}_{2}\right)$ sebesar 2.541 sedangkan $t_{\text {tabel }}$ sebesar 1.987, dengan demikian $t_{\text {hitung }} 2.541>t_{\text {tabel }}$ 1.987 dan nilai signifikansi sebesar 0,013 ( sig < 0,05). Berdasarkan analisis di atas 
disimpulkan bahwa faktor eksternal berpengaruh secara signifikan terhadap entrepreneurial intentions mahasiswa di Pekanbaru sehingga hipotesis ini telah teruji secara empiris.

Uji F

Tabel 2: ANOVA

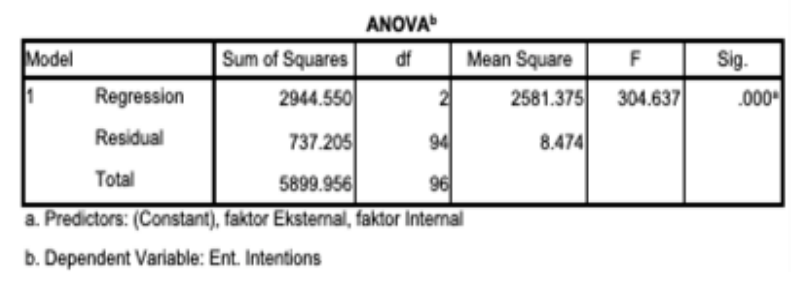

Nilai $F$ tabel pada taraf kepercayaan signifikansi 0,05 adalah 3.09 dengan demikian $\mathrm{F}_{\text {hitung }}=304.637>\mathrm{F}$ tabel $=3.09$ dengan tingkat signifikansi $0,000<0,05$ menunjukkan bahwa variabel bebas faktor internal dan faktor eksternal secara simultan berpengaruh terhadap entrepreneurial intentions Mahasiswa di Pekanbaru

Uji Koefisien Determinasi $\left(\mathrm{R}^{2}\right)$

Berdasarkan hasil perhitungan koefisien determinasi nilai adjusted $\mathrm{R}^{2}$ sebesar 0.669 dengan nilai Standard Error 2.940. Dengan demikian dapat ditegaskan bahwa $66,9 \%$ entrepreneurial intentions ditentukan oleh faktor internal $\mathrm{X}_{1}$ (motivasi, kepribadian, orientasi kerja, kreatifitas dan inovasi, orientasi masa depan) dan eksternal $\mathrm{X}_{2} \quad$ (lingkungan keluarga \& sosial, lingkungan akademik, lingkungan teknologi) sisanya $33,1 \%$ dipengaruhi oleh variabel lain yang tidak diamati dalam penelitian ini

\section{PEMBAHASAN}

Entrepreneurial Intentions sudah banyak diteliti di Negara Barat, beberapa peneliti sebelumnya di bidang kewirausahaan diantaranya Carr dan Sequeira (2007), Kautonen et al (2010), serta Schwarz et al (2009) dan peneliti lainnya. Namun di Indonesia sendiri, penelitian terkait Kewirausahaan masih terbatas meskipun kewirausahaan telah dipandang penting dalam pengembangan dan pertumbuhan ekonomi.

Dilihat dari sosio demografi, pada kajian ini mahasiswa dan mahasiswi mempunyai ketertarikan yang sama terhadap kewirausahaan. Beberapa kajian terdahulu memperlihatkan pengaruh faktor gender terhadap entrepreneurial intentions, yaitu mahasiswa dengan jenis kelamin lakilaki memiliki niat berwirausaha yang lebih tinggi daripada mahasiswi perempuan (Rasheed, 2000; Nishanta, 2008). Namun hal yang sama tidak ditemukan dalam studi Johnston et al. (2010).

Temuan menarik terkait dengan latar belakang pendidikan mahasiswa menunjukkan bahwa mahasiswa di Pekanbaru yang berasal dari Jurusan Ekonomi tidak terlalu berminat untuk menjadi wirausaha. Berdasarkan wawancara langsung, beberapa mahasiswa mengemukakan bahwa masih minimnya orientasi terkait kewirausahaan di perguruan tinggi tempat mereka mengenyam pendidikan. Terlebih para mahasiswa merasa bahwa kurikulum program studi memang belum dan tidak diarahkan untuk membentuk entrepreneurs akan tetapi lebih membekali mahasiswa untuk siap kerja di perusahaan multinasional dan hidup mapan.

Dalam penelitian ini, faktor internal memiliki pengaruh yang lebih besar daripada faktor Eksternal terhadap entrepreneurial intentions di kalangan mahasiswa di Pekanbaru. Sebagian besar mahasiswa mengaku memiliki niat untuk berwirausaha karena tidak ingin bergantung pada orang lain dan ingin menjadi pelopor. Hanya saja dari sisi kreatifitas dan inovasi masih terbilang rendah karena mahasiswa merasa tujuan utama mengenyam pendidikan tinggi adalah untuk menjadi pegawai bukan menjadi wirausaha terlebih dari sisi kurikulum perguruan tinggi, kreatifitas dan inovasi untuk berwirausaha tidak begitu dipupuk untuk dikembangkan.

Dari segi faktor Eksternal, lingkungan akademik bisa dikatakan tidak mempengaruhi mahasiswa untuk berwirausaha. Lagi-lagi, orientasi dan kurikulum pendidikan tinggi yang memang belum berorientasi akan penciptaan lulusan 
yang mampu menciptakan lapangan kerja, melainkan menghasilkan lulusan yang siap diterima di dunia kerja.

Beberapa mahasiswa yang sudah mendapatkan mata kuliah kewirausahaan mengaku bahwa mata kuliah yang disajikan tidak menarik. Dosen pengampu mata kuliah Kewirausahaan bukan dosen dengan background study kajian ilmu bisnis dan juga bukan professional, sehingga materi perkuliahan terlalu teoritis sesuai textbook, tidak memotivasi dan tidak implementatif dengan keadaan saat ini.

Sisi menarik berasal dari lingkungan teknologi, kemajuan perkembangan teknologi dan kemudahan penggunaan internet saat ini dirasa mahasiswa mampu menumbuhkan niat untuk menjadi wirausaha. $6 \%$ dari responden yang memiliki pengalaman kerja lainnya merupakan mahasiswa yang memiliki bisnis online secara otodidak tanpa bekal pembelajaran kewirausahaan dari perguruan tinggi.

Sebagian besar mahasiswa mengaku latar belakang pekerjaan orang tua dan kondisi ekonomi keluarga mempengaruhi gambaran terkait masa depan dan pekerjaan yang akan mereka tekuni di masa mendatang. Sejalan dengan yang dikatakan oleh Wibowo (2011) terkait teori konvergensi bahwa Individu yang tumbuh di lingkungan pedagang secara relatif akan mempunyai kesempatan yang lebih besar untuk menjadi pedagang. Jiwa kewirausahaan bisa tumbuh dan berkembang karena pengaruh lingkungan fisik di sekitar individu tersebut.

Begitu pula halnya dengan motivasi dari teman yang sudah memiliki usaha, memiliki dampak yang lebih besar daripada pengaruh pembelajaran di perguruan tinggi. Beberapa mahasiswa mengaku lebih tertarik untuk memulai usaha karena melihat kesuksesan teman atau kenalan yang sudah menjadi wirausaha. Jadi dapat dikatakan, lingkungan akademik perguruan tinggi di Pekanbaru sampai saat ini masih belum memiliki kontribusi terhadap entrepreneurial intentions di kalangan mahasiswa.

\section{SIMPULAN}

Berdasarkan data-data hasil penelitian serta analisis yang telah dilakukan pada penelitian ini, maka kesimpulan yang dapat menjawab perumusan masalah penelitian yakni sebagai berikut: Secara parsial, faktor internal (motivasi, kepribadian, orientasi kerja, kreatifitas dan inovasi) berpengaruh signifikan terhadap entrepreneurial intentions di kalangan mahasiswa perguruan tinggi di Pekanbaru.

Secara parsial, faktor eksternal (lingkungan keluarga dan sosial, lingkungan akademik, lingkungan teknologi) berpengaruh signifikan terhadap entrepreneurial intentions di kalangan mahasiswa di Pekanbaru. Faktor internal dan eksternal secara simultan berpengaruh signifikan terhadap entrepreneurial intentions di kalangan mahasiswa di Pekanbaru. Variabel faktor internal dan eksternal memiliki kontribusi pengaruh sebesar $66,9 \%$ terhadap entrepreneurial intentions di kalangan mahasiswa perguruan tinggi di Pekanbaru

\section{DAFTAR RUJUKAN}

AlHaj, B. K., Yusof, M. Z., \& Edama, N. (2011). Entrepreneurial intention: An empirical study of community college students in Malaysia. Jurnal Personalia Pelajar (14), 4558.

Azwar, Saifuddin. (2010). Reliabilitas dan Validitas. Yogyakarta: Pustaka Pelajar.

Berglund, K., \& Johansson, A. W. (2007). The entrepreneurship discourse: Outlined from diverse constructions of entrepreneurship on the academic scene. Journal of Enterprising Communities: People and Places in the Global Economy, 1(1), 77-102. 
Boulton, C. and Turner, P. (2005). Mastering Business in Asia: Entrepreneurship. Singapore: John Wiley and Sons.

Carr, J.C. and Sequeira, J.M. (2007). Prior Family Business Exposure as Intergenerational Influence and Entrepreneurial Intent: A Theory of Planned Behavior Approach. Journal of Business Research, 60: 1090-1098.

Choo, S., dan M. Wong. (2006). Entrepreneurial intention: triggers and barriers to new venture creations in Singapore. Singapore Management Review 28 (2): 47-64.

Elfving, J., Brännback, M., \& Carsrud, A. (2009). Toward a contextual model of entrepreneurial intentions Understanding the entrepreneurial mind (pp. 23-33): Springer.

Galloway. L, Kelly.S. \& Keogh. W. 2006. Identifying Entrepreneurial Potential in Students. Working Paper No. 006, National Council for Graduate Entrepreneurship.

Gerry. C, Susana. C. \& Nogueira. F. (2008). Tracking Student Entrepreneurial Potential: Personal Attributes and the Propensity for Business StartUps after Graduation in a Portuguese University. International Research Journal Problems and Perspectives in Management, 6(4): 45-53.

Giles, M., dan A, Rea. (1970) Career selfefficacy: an application of the theory of planned behavior. Journal of Occupa- tional \& Organizational Psychology 73 (3): 393-399.

Global Entrepreneurship Monitor (GEM). 2018. Global Report 2018/2019. Babson College: USA
Gurbuz, G., \& Aykol, S. (2008). Entrepreneurial intentions of young educated public in Turkey. Journal of Global Strategic Management, 4(1), 47-56.

Indarti, N. (2004). Factors affecting entrepreneurial intentions among Indonesian students. Jurnal Ekonomi dan Bisnis 19 (1): 57-70.

Johnston, K.A, Andersen, B.K., DavidgePitts, J. \& Ostensen-Saunders, M. (2010). Identifying ICT Entrepreneurship Potential in Students. Paper was presented at the Proceedings of Informing Science \& IT Education Conference (InSITE), Italy, 21-24 Juni.

Kautonen, T., Luoto, S. and Tornikoski, E.T. (2010). Influence of Work History on Entrepreneurial Intentions in 'Prime Age' and 'Third Age': A Preliminary Study. International Small Business Journal, 28(6):583-601.

Kautonen, T., Tornikoski, E.T. and Kibler, E. (2009). Entrepreneurial Intentions in the Third Age: The Impact of Perceived Age Norms, Small Business Economics. published online 18 October 2009, DOI: $10.1007 / \mathrm{s} 11187-009-9238-\mathrm{y}$.

Kobia, M. and Sikalieh, D. (2010), Towards a Search for The Meaning of Entrepreneurship. Journal of European Industrial Training. 34(2): 110-127.

Koe, W.L., Sa'ari, J.R., Majid, I.A., Ismail, K. (2012). Determinants of Entrepreneurial Intention among Millennial Generation, Procedia Social and Behavioral Sciences, Vol. 40, pp. 197-208. 
Kristiansen, S. (2001). Promoting African pioneers in business: what makes a context conducive to small-scale entrepreneurship? Journal of Entrepreneurship 10 (1): 43-69.

Kristiansen, S. (2002a). Individual perception of business contexts: the case of small scale entrepreneurs in Tanzania. Journal of Developmental Entrepreneurship 7 (3).

Kristiansen, S. (2002b). Competition and knowledge in Javanese rural business'. Singapore Journal of Tropical Geography 23 (1): 52-70.

Kristiansen, S., B. Furuholt, dan F. Wahid. (2003). Internet cafe entrepreneurs: pioneers in information dissemination in Indonesia. The International Journal of Entrepreneurship and Innovation 4 (4): 251-263.

Krueger, N. F. dan A. L. Carsrud. (1993). Entrepreneurial intentions: applying the theory of planned behavior. Entrepreneurship \& Regional Development 5 (4): 315-330.

Krueger, N., Reilly, M. and Carsrud, A. (2000). Competing models of entrepreneurial intentions. Journal of Business Venturing, 15(2), 41132.

Lee, S.H. \& Wong, P.K. (2004). An Exploratory Study of Technopreneurial Intentions: A Career Anchor Perspective. Journal of Business Venturing, 19(1): 7-28.

McClelland, D. (1971). The Achievement Motive in Economic Growth, in: P. Kilby (ed.) Entrepreneurship and Economic Development. New York The Free Press, 109-123.
Mellor, R., Coulton, G., Chick, A. Bifulco, A., Mellor, N. and Fisher, A. (2009), Entrepreneurship for Everyone. London: SAGE Publications.

Moriano, J.A., Gorgievski, M., Laguna, M., Stephan, U. and Zarafshani, K. (2011), A Cross-cultural Approach to Understanding Entrepreneurial Intention, Journal of Career Development, published online 6 January 2011, DOI: $10.1177 / 089484845310384481$.

Nishanta, B. (2008). Influence of Personality Traits and Sociodemographic Background of Undergraduate Students on Motivation for Entrepreneurial Career: The Case of Srilanka. Paper was presented at the EuroAsia Management Studies Association (EAMSA) Conference, Japan.

Priyanto S.H. (2008). Di dalam Jiwa ada Jiwa: The Backbone and the Social Construction

Entrepreneurships. Pidato Pengukuhan Guru Besar Universitas Kristen Satya Wacana.

Rasheed, H.S. (2000). Developing Entrepreneurial Potential in Youth: The Effects of Entrepreneurial Education and Venture Creation. International Journal of Entrepreneurship Educations

Schwarz, E.J., Wdowiak, M.A., Almer-Jarz, D.A. and Breitenecker, R.J. (2009), The Effects of Attitudes and Perceived Environment Conditions on Students' Entrepreneurial Intent: An Austrian Perspective. Education + Training, 51(4): 272-291. 
Sengupta, S. K. dan S. K. Debnath. (1994). Need for achievement and entrepreneurial success: a study of entrepreneurs in two rural industries in West Bengal. The Journal of Entrepreneurship 3 (2): 191-204.

Sinha, T. N., (1996). Human factors in entrepreneurship effectiveness. Journal of Entrepreneurship 5(1): 23-29.

Suryana. (2014). Kewirausahaan. Jakarta: Salemba Empat.

Tjahjono, H.K. \& Ardi, H. (2008). Kajian Niat Mahasiswa Manajemen Universitas Muham- madiyah Yogyakarta untuk Menjadi Wirausaha. Utilitas Jurnal Manajemen dan Bisnis, 16(1): 4663.

van Gelderen, M., Brand, M., van Praag, M., Bodewes, W., Poutsma, E. and van Gils, A. (2008). Explaining Entrepreneurial Intentions by Means of the Theory of Planned Behavior. Career Development International, 13(6): 538-559.

Walgito, Bimo. (2004). Pengantar Psikologi Umum. Yogyakarta: ANDI OFFSET.

Wibowo. (2011). Manajemen Kinerja. Jakarta: Raja Grafindo Persada.

$\mathrm{Wu}, \mathrm{S} . \& \mathrm{Wu}, \mathrm{L}$. (2008). The Impact of Higher Education on Entrepreneurial Intentions of University Students in China. Journal of Small Business and Enterprise Development, 15(4): 752-774.

Yohnson. (2003). Peranan Universitas dalam Memotivasi Sarjana Menjadi Young Entrepreneurs. Jurnal
Manajemen dan Kewirausahaan, 5(2): 97-111.

Yuriski, Handres. (2009). Analisis FaktorFaktor Yang Mempengaruhi Persepsi dan Minat Mahasiswa Untuk Berwirausaha: Studi Mahasiswa Universitas Andalas. Universitas Andalas.

Zimmerer, W.T. (2002). Essentials of Entrepreneurship and Small Business Management. Third Edition. New York: Prentice-Hall. 